\title{
Ranking the dietary treatments of broiler chickens in order to reduce nitrogen pollution of the environment
}

\author{
GABRIELA GEANINA VASILE ${ }^{1}$, ANDA GABRIELA TENEA ${ }^{1}$, \\ ECATERINA ANCA SERBAN ${ }^{1}$, GINA ALINA CATRINA ${ }^{1}$, VALERIU BADESCU ${ }^{1 *}$, \\ PETRU ALEXANDRU VLAICU ${ }^{2}$
}

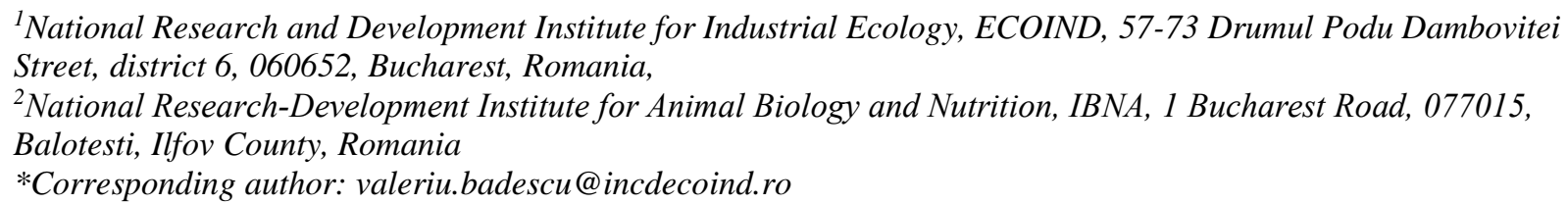

$\begin{array}{ccc}\text { Received: } & \text { Accepted: } & \text { Published: } \\ \text { 06.10.2021 } & 16.11 .2021 & 17.12 .2021\end{array}$

\begin{abstract}
The Analytical Hierarchy Process (AHP) methodology was used to rank the tested nutritional solutions and to choose the best nutritional solution in order to reduce environmental pollution with nitrogen. The evaluation methodology consisted in comparing by three evaluators the diets based on the zootechnical performances / thigh meat quality / environmental impact.

The diets of tested nutritional solutions were contained either medicinal and aromatic plants (basil, thyme, sage) in a proportion of $1 \%$ (batch 2), respectively essential oils $(0.05 \%)$ of the same plants (batch 1). The application of the AHP methodology indicated that the best nutritional alternative was obtained for basil, either in the form of essential oil or vegetal material.
\end{abstract}

Keywords: AHP, broiler chickens, herbal plants, nutritional solution, oil

\section{INTRODUCTION}

In general, the addition of antioxidants as nutritional supplements to the animal's diet is a common practice to improve animal performance, health, and welfare. For monogastric animals (i.e., broiler chickens, laying hens, pigs), natural antioxidants added to feed not only improve the oxidative stability and organoleptic properties, but can also improve the nutritional value and benefits of meat products for human health [1]. There has been a growing interest in supplementing feed with antioxidant plant extracts or raw antioxidant plant materials to increase the nutritional value of meat with beneficial effects on consumer health. For example, rosemary leaves [2], grape seed extract [3], liquorice extract [4] and thyme as additives help eliminate free radicals. In addition, has been shown that improved diets lead to decrease lipid oxidation, improve the quality of meat by increasing the stability of antioxidants in meat. Higher concentration of polyphenolic antioxidants was reported to delay deterioration of the meat color [3]. Basil (Ocimum spp., Lamiaceae), rosemary (Rosmarinus officinalis), thyme (Thymus vulgaris), marjoram (Origanum majorana), sage (Salvia officinalis), oregano (Origanum vulgare) have a strong antioxidant character [5, 6].

Basil have many essential oils rich in phenolic compounds such as flavonoids and anthocyanins and for this reason, basil was used in chickens diet with great results [7-9]. Therefore, inclusion of basil concentration up to $1.5 \%$ lead to an increased performance such as significant body weight ( $p$ $<0.05)$ and conversion rate of feed $[7,8]$.

Thyme supplementation in the broiler nutrition proved to improve chickens health as result of antibacterial, anticoccidial and antifungal activities [10]. The digestion and the entire intestinal system are influenced by the active principles of thyme oil and thus is stimulates the secretion of 
digestive enzymes that lead to increased zootechnical performance [11]. Thyme can be used as a source of natural antioxidants and antibiotics in nutritional diet for chickens. Some studies demonstrate the antioxidant and immunostimulatory potential of thyme, observed in health and performance indicators of broilers [12].

Rasouli et al. proved the link between the immunity of chicks and the antibacterial activity of sage extract, as result of inclusion in the diet [13]. Significant improvement ( $p$ value < 0.05 ) of red blood cell count and hemoglobin was demonstrated by Al-Sherify and Al-Alwany after addition of $1 \%$ and $2 \%$ of Salvia officinalis leaf powder in the diet of broiler chickens Ross 308 [14].

The Analytical Hierarhy Process (AHP) is a theory that combine mathematics and psychology in order to help decision makers to select the best option in a specific field. This theory of measurement, which is based on pairwise comparison and judgements of experts, divide the problematic in the following steps: problem definition; hierarchy in main objective/ characteristic, intermediate objective and lower objective; construction of comparison matrices; calculating the weight for each objective as a result of prioritization $[15,16]$.

AHP methodology has been successfully applied not only in the zootechnics field, but also in many other domains, such as environment (land use pattern selection), agriculture (harvesting measure selection), military (nuclear fuel cycle selection), manufacturing (maintenance strategy selection), business (resource allocation), logistics (transportation route selection), health-care and higher education (IT-based project selection) [17-21].

The objective of the study was to establish new nutritional complex feeding diets with innovative character for broiler chickens, friendly to animals, humans and the environment, based on zootechnical performance / thigh meat quality / environmental impact, which could be recommended to farmers in order to reduce the nitrogen pollution of the environment. The best nutritional solution was selected using AHP methodology.

\section{MATERIALS AND METHODS}

The nutritional solutions used for broiler chickens feeding were included along with the control diet (corn, wheat, soybeans), herbal plants (as such or as an oil extract), other components as are presented in table 1.

Two experimental batches were performed, one with oil herbal plants (Batch 1), and another with herbal plant as dietary supplements (Batch 2). Each batch contained one control (without herbal plants in diet) and experimental diets with three different plants: basil, thyme and sage.

Table 1. Nutritional solutions (NS) for broiler chickens

Batch $1 \quad$ Batch 2

\begin{tabular}{l|l}
\hline NS-Control - corn, wheat, soybeans + 5\% Alfalfa meal + 0.1\% Acidified (Biotronic Top3) \\
\hline NS-Eo1 - corn, wheat, soybeans + 5\% alfalfa & NS-E1 - corn, wheat, soybeans + 5\% alfalfa \\
meal + 0.1\% Acidified+ 0.05\% basil oil & meal + 0.1\% Acidified+1\% basil \\
NS-Eo2 - corn, wheat, soybeans + 5\% alfalfa & NS-E2 - corn, wheat, soybeans + 5\% alfalfa \\
meal + 0.1\% Acidified + 0.05\% thyme oil & meal + 0.1\% Acidified + 1\% thyme \\
NS-Eo3 - corn, wheat, soybeans + 5\% alfalfa & NS-E3 - corn, wheat, soybeans + 5\% alfalfa \\
meal + 0.1\% Acidified+ 0.05\% sage oil & meal + 0.1\% Acidified + 1\% sage \\
\hline
\end{tabular}

AHP methodology used the Saaty Scale for comparisons [15]. This scale indicates how many times more important is one object compare with another object. The object could be an element, a parameter, a category, a criterion, a characteristic, etc. 
Table 2. The scale of the importance intensity (Saaty Scale)

\begin{tabular}{l|l}
\hline $\begin{array}{c}\text { The intensity } \\
\text { of importance* }\end{array}$ & \\
\hline 1 & Equal importance \\
3 & Slightly more important than each other (A slightly more important than B) \\
5 & Essential or strong importance (A more important than B) \\
7 & Demonstrated importance (A much more important than B) \\
9 & Absolute importance (A absolutely more important than B) \\
$2,4,6,8$ & Intermediate values between two adjacent evaluations \\
\hline
\end{tabular}

* The assigned value given to the comparison evaluation of two objects or values (A and $\mathrm{B}$ ).

Three criteria were considered for the implementation of the AHP methodology, namely: zootechnical performance, thigh meat quality and environmental impact.

Regarding the zootechnical performance criterion $C 1$, the results of the technical indicators were taken into account: the average daily weight gain (ADWG), the total increase and the final body weight.

ADWG can be defined as the average amount of weight a market animal will gain each day during the feeding period. ADWG can be calculated by taking the amount of weight an animal has gained since the last weight and dividing the weight by the number of days since that last weight. The body weight of animals is an important marker that can characterize the influence of dietary supplements on productive performance of animals.

The thigh meat quality criterion $C 2$ consist in antioxidant capacity and concentration in total polyphenols. Antioxidant capacity, polyphenols concentrations are nutritional parameters which indicate the quality of animal products in terms of antioxidant compounds.

The ecological criterion $C 3$ could be given by the value of nitrogen digestibility coefficient or by the total nitrogen concentration in manure. The degree of absorption of a specific compound in the animal body is given by the digestibility coefficient, in this case the nitrogen digestibility coefficient. By using the data obtained measuring the digestibility coefficients of nutrients, it can be appreciating the absorption degree of interest compound in the animal organism.

Finally, the average daily weight gain $(\mathrm{C} 1)$, antioxidant capacity of the chicken thigh meat $(\mathrm{C} 2)$ and total nitrogen concentration in manure (batch 1) or the nitrogen digestibility coefficient (batch 2) (C3) were selected for AHP evaluation methodology.

\section{RESULTS AND DISCUSSION}

The results of the average daily weight gain $(\mathrm{C} 1)$, antioxidant capacity of the chicken thigh meat (C2) and the nitrogen digestibility coefficient (C3) are presented in table 3.

The evaluation methodology consisted in pairwise comparisons carrying out by a group of evaluators in order to express the relative importance of the criteria and nutritional solutions considered. The analysis panel has been formed from three relevant evaluators, one from IBNA Balotesti and two from ECOIND Bucharest.

Each evaluator completed a type A ( $3 \times 3)$ evaluation matrix regarding the relative importance of the criteria and a type A $(3 \times 3)$ evaluation matrix regarding the relative importance of the nutritional solutions.

Each evaluator established a ranking of the criteria considered for reducing nitrogen pollution of the environment, taking into account the scale of the importance intensity (Saaty Scale). Thus, for example, the first evaluator established that the order of criteria importance is: $\mathrm{C} 3>\mathrm{C} 2>\mathrm{C} 1$. Using the intensity scale (table 3), evaluator 1 established that $\mathrm{C} 3$ criterion is 7 times more important than $\mathrm{C} 1$ criterion, respectively 5 times more important than $\mathrm{C} 2$ criterion, and $\mathrm{C} 2$ is 3 times more important than $\mathrm{C} 1$. 
Table 3. Results of the selected criteria for both lots $(n=10, p$ value $>0.05)$

\begin{tabular}{|c|c|c|c|c|c|}
\hline Criterion & $\begin{array}{c}\text { Measure } \\
\text { unit }\end{array}$ & Control & Eo1 & Eo2 & Eo3 \\
\hline \multicolumn{6}{|l|}{ Batch 1} \\
\hline Average daily weight gain $(\mathrm{C} 1)$ & $\mathrm{g}$ & $86.89 \pm 0.65$ & $87.57 \pm 0.71$ & $86.10 \pm 0.69$ & $85.24 \pm 0.55$ \\
\hline $\begin{array}{l}\text { Antioxidant capacity of the } \\
\text { chicken thigh meat }(\mathrm{C} 2)\end{array}$ & $\begin{array}{l}\mathrm{mM} \\
\text { Trolox }\end{array}$ & $1.74 \pm 0.076$ & $1.98 \pm 0.168$ & $2.04 \pm 0.343$ & $1.88 \pm 0.076$ \\
\hline $\begin{array}{l}\text { Total nitrogen content in } \\
\text { manure }(\mathrm{C} 3)\end{array}$ & $\%$ & $4.52 \pm 0.21$ & $4.535 \pm 0.05$ & $4.72 \pm 0.15$ & $4.705 \pm 0.45$ \\
\hline Batch 2 & & Control & E1 & $\mathbf{E 2}$ & $\mathbf{E 3}$ \\
\hline Average daily weight gain $(\mathrm{C} 1)$ & $\mathrm{g}$ & $82.54 \pm 1.07$ & $81.72 \pm 1.03$ & $83.06 \pm 1.09$ & $80.26 \pm 1.01$ \\
\hline $\begin{array}{l}\text { Antioxidant capacity of the } \\
\text { chicken thigh meat }(\mathrm{C} 2)\end{array}$ & $\begin{array}{l}\mathrm{mM} \\
\text { Trolox }\end{array}$ & $2.49 \pm 0.09$ & $2.59 \pm 0.067$ & $2.562 \pm 0.083$ & $2.658 \pm 0.143$ \\
\hline $\begin{array}{l}\text { Nitrogen } \\
\text { coefficient (C3) }\end{array}$ & $\%$ & $88.09 \pm 1.49$ & $89.72 \pm 1.72$ & $88.19 \pm 1.80$ & $88.78 \pm 1.87$ \\
\hline
\end{tabular}

In the same way, evaluators 2 and 3 ranked the criteria and the numerical data are presented in the table 4.

Table 4. Pairwise comparison matrix of the main criteria

\begin{tabular}{l|ccccccccc}
\hline Evaluator & \multicolumn{4}{|c}{ Evaluator 1 } & \multicolumn{3}{c}{ Evaluator 2 } & \multicolumn{3}{c}{ Evaluator 3 } \\
\hline Criterion & C1 & C2 & C3 & C1 & C2 & C3 & C1 & C2 & C3 \\
C1 & 1 & $1 / 3=0.33$ & $1 / 7=0.14$ & 1 & 3 & $1 / 5=0.20$ & 1 & $1 / 3=0.33$ & $1 / 8=0.13$ \\
C2 & 3 & 1 & $1 / 5=0.20$ & $1 / 3=0.33$ & 1 & $1 / 7=0.14$ & 3 & 1 & $1 / 6=0.17$ \\
C3 & 7 & 5 & 1 & 5 & 7 & 1 & 8 & 6 & 1 \\
\hline
\end{tabular}

By processing the data from table 4, the influence weights of each criterion were obtained (table 5). These weights were used to establish the final decision, which is selection of the best nutritional solution for broiler chickens with lower effect regarding nitrogen pollution of the environment.

Table 5. Priorities for each criterion

\begin{tabular}{l|ccc}
\hline \multicolumn{1}{c}{ Evaluator / Criterion } & C1 & C2 & C3 \\
\hline Evaluator 1 & 0.081 & 0.188 & 0.731 \\
Evaluator 2 & 0.081 & 0.188 & 0.731 \\
Evaluator 3 & 0.073 & 0.166 & 0.761 \\
\hline
\end{tabular}

Next step was to establish an evaluation matrix type A $(3 \times 3)$ regarding the importance of nutritional solutions used for broiler chickens using same intensity scale (table 3) for each batch.

Batch 1 results

For batch 1 results, depending on the values of the three indicators (table 3) namely: the average daily weight gain $(\mathrm{C} 1)$, antioxidant capacity of the chicken thigh meat $(\mathrm{C} 2)$ and the total nitrogen concentration in manure (C3), the evaluators established an order of importance for each criterion. Thus, for criterion 1, the order was Eo1> Eo2> Eo3; for criterion 2, the order was Eo2> Eo1> Eo3; finally, for criterion 3 the order was Eo1> Eo3> Eo2. The values assigned by the evaluators for each nutritional solution are presented in table 6 .

As a result of processing the values from the table 6, the weights for each nutritional solution were obtained and their hierarchy was achieved (Table 7). Subsequently, the obtained data were combined both from criteria and nutritional solutions ranking. 
Table 6. Pairwise comparison matrix of the nutritional solutions - herbal plants oil

\begin{tabular}{|c|c|c|c|c|c|c|c|c|c|}
\hline \multicolumn{10}{|c|}{ Evaluator 1} \\
\hline Criterion & \multicolumn{3}{|c|}{ Criterion 1} & \multicolumn{3}{|c|}{ Criterion 2} & \multicolumn{3}{|c|}{ Criterion 3} \\
\hline \multirow[t]{2}{*}{ NS } & NS- & NS- & NS- & NS- & NS- & NS- & NS- & NS- & NS- \\
\hline & Eo1 & Eo2 & Eo3 & Eo1 & Eo2 & Eo3 & Eo1 & Eo2 & Eo3 \\
\hline NS-Eo1 & 1 & 5 & 7 & 1 & $1 / 3$ & 5 & 1 & 8 & 6 \\
\hline NS-Eo2 & $1 / 5$ & 1 & 3 & 3 & 1 & 8 & $1 / 8$ & 1 & $1 / 3$ \\
\hline NS-Eo3 & $1 / 7$ & $1 / 3$ & 1 & $1 / 5$ & $1 / 8$ & 1 & $1 / 6$ & 3 & 1 \\
\hline \multicolumn{10}{|c|}{ Evaluator 2} \\
\hline Criterion & \multicolumn{3}{|c|}{ Criterion 1} & \multicolumn{3}{|c|}{ Criterion 2} & \multicolumn{3}{|c|}{ Criterion 3} \\
\hline \multirow[t]{2}{*}{$\mathbf{N S}$} & NS- & NS- & NS- & NS- & NS- & NS- & NS- & NS- & NS- \\
\hline & Eo1 & Eo2 & Eo3 & Eo1 & Eo2 & Eo3 & Eo1 & Eo2 & Eo3 \\
\hline NS-Eo1 & 1 & 4 & 6 & 1 & $1 / 2$ & 5 & 1 & 9 & 7 \\
\hline NS-Eo2 & $1 / 4$ & 1 & 2 & 2 & 1 & 7 & $1 / 9$ & 1 & $1 / 3$ \\
\hline NS-Eo3 & $1 / 6$ & $1 / 2$ & 1 & $1 / 5$ & $1 / 7$ & 1 & $1 / 7$ & 3 & 1 \\
\hline \multicolumn{10}{|c|}{ Evaluator 3} \\
\hline Criterion & \multicolumn{3}{|c|}{ Criterion 1} & \multicolumn{3}{|c|}{ Criterion 2} & \multicolumn{3}{|c|}{ Criterion 3} \\
\hline NS & NS- & NS- & NS- & NS- & NS- & NS- & NS- & NS- & NS- \\
\hline & Eo1 & Eo2 & Eo3 & Eo1 & Eo2 & Eo3 & Eo1 & Eo2 & Eo3 \\
\hline NS-Eo1 & 1 & 5 & 7 & 1 & $1 / 3$ & 7 & 1 & 8 & 6 \\
\hline NS-Eo2 & $1 / 5$ & 1 & 2 & 3 & 1 & 9 & $1 / 8$ & 1 & $1 / 2$ \\
\hline NS-Eo3 & $1 / 7$ & $1 / 2$ & 1 & $1 / 7$ & $1 / 9$ & 1 & $1 / 6$ & 2 & 1 \\
\hline
\end{tabular}

Table 7. Hierarchy of the nutritional solutions based on herbal plants oil

\begin{tabular}{c|cccc}
\hline Evaluator 1 & C1 & C2 & C3 & Hierarchy \\
\hline Ev1C & $\mathbf{0 . 0 8 1}$ & $\mathbf{0 . 1 8 8}$ & $\mathbf{0 . 7 3 1}$ & \\
NS-Eo1 & 0.731 & 0.272 & 0.761 & $\mathbf{0 . 6 6 7}$ \\
NS-Eo2 & 0.188 & 0.661 & 0.073 & $\mathbf{0 . 1 9 3}$ \\
NS-Eo3 & 0.081 & 0.067 & 0.166 & $\mathbf{0 . 1 4 1}$ \\
\hline
\end{tabular}

\begin{tabular}{c|cccc}
\hline Evaluator 2 & C1 & C2 & C3 & Hierarchy \\
\hline Ev2C & $\mathbf{0 . 1 8 8}$ & $\mathbf{0 . 0 8 1}$ & $\mathbf{0 . 7 3 1}$ & \\
NS-Eo1 & 0.701 & 0.333 & 0.785 & $\mathbf{0 . 7 3 3}$ \\
NS-Eo2 & 0.193 & 0.592 & 0.066 & $\mathbf{0 . 1 3 2}$ \\
NS-Eo3 & 0.106 & 0.075 & 0.149 & $\mathbf{0 . 1 3 5}$ \\
\hline
\end{tabular}

\begin{tabular}{c|cccc}
\hline Evaluator 3 & C1 & C2 & C3 & Hierarchy \\
\hline Ev3C & $\mathbf{0 . 0 7 3}$ & $\mathbf{0 . 1 6 6}$ & $\mathbf{0 . 7 6 1}$ & \\
NS-Eo1 & 0.740 & 0.290 & 0.769 & $\mathbf{0 . 6 8 7}$ \\
NS-Eo2 & 0.167 & 0.655 & 0.084 & $\mathbf{0 . 1 8 5}$ \\
NS-Eo3 & 0.094 & 0.055 & 0.147 & $\mathbf{0 . 1 2 8}$ \\
\hline
\end{tabular}

The weights resulting from the combination of the values assigned for the hierarchy of the criteria, respectively of the nutritional solutions were calculated with the formula (1):

where:

$$
N S-E o 1_{\text {final }}=\sum_{n=1}^{3}\left(\operatorname{EvnC}_{n} x N S_{E o n C n}\right) \text {, }
$$

EvnC $_{n}$ represent the weight of $C_{n}$ assigned by the evaluator $n$;

$\mathrm{NS}_{\mathrm{EonCn}}$ represent the weight of nutritional solution $\mathrm{Eo}_{\mathrm{n}}$ assigned by the evaluator Evn for criterion $\mathrm{C}_{\mathrm{n}}$.

The average value of the final weights obtained for the three nutritional solutions indicates that NSEo1 (0.723) is better than NS-Eo3 (0.141) which is approximately the same as NS-Eo2 (0.136). In 
this case, the best alternative for feeding the broiler chickens in order to reduce the nitrogen pollution of the environment is NS-Eo1, which uses $0.05 \%$ basil oil as a supplement.

Batch 2 results

For batch 2, the average daily weight gain (C1), antioxidant capacity of the chicken thigh meat (C2) and the nitrogen digestibility coefficient (C3) were selected as criteria. The evaluators established an order of importance for each criterion as follows: for criterion 1, the order was E2> E1> E3; for criterion 2, the order was E3> E2> E1; finally, for criterion 3 the order was E1>E3> E2.

The values assigned by the evaluators for each nutritional solutions were presented in table 8 , respectively in table 9 the hierarchy of the same diets.

Table 8. Pairwise comparison matrix of the nutritional solutions - herbal plants oil

\begin{tabular}{|c|c|c|c|c|c|c|c|c|c|}
\hline \multicolumn{10}{|c|}{ Evaluator 1} \\
\hline Criterion & \multicolumn{3}{|c|}{ Criterion 1} & \multicolumn{3}{|c|}{ Criterion 2} & \multicolumn{3}{|c|}{ Criterion 3} \\
\hline NS & NS-E1 & NS-E2 & NS-E3 & NS-E1 & NS-E2 & NS-E3 & NS-E1 & NS-E2 & NS-E3 \\
\hline NS-E1 & 1 & $1 / 3$ & 3 & 1 & $1 / 3$ & $1 / 7$ & 1 & 9 & 6 \\
\hline NS-E2 & 3 & 1 & 5 & 3 & 1 & $1 / 5$ & $1 / 9$ & 1 & $1 / 3$ \\
\hline NS-E3 & $1 / 3$ & $1 / 5$ & 1 & 7 & 5 & 1 & $1 / 6$ & 3 & 1 \\
\hline \multicolumn{10}{|c|}{ Evaluator 2} \\
\hline Criterion & \multicolumn{3}{|c|}{ Criterion 1} & \multicolumn{3}{|c|}{ Criterion 2} & \multicolumn{3}{|c|}{ Criterion 3} \\
\hline NS & NS-E1 & NS-E2 & NS-E3 & NS-E1 & NS-E2 & NS-E3 & NS-E1 & NS-E2 & NS-E3 \\
\hline NS-E1 & 1 & $1 / 3$ & 2 & 1 & $1 / 2$ & $1 / 7$ & 1 & 8 & 5 \\
\hline NS-E2 & 3 & 1 & 4 & 2 & 1 & $1 / 5$ & $1 / 8$ & 1 & $1 / 3$ \\
\hline NS-E3 & $1 / 2$ & $1 / 4$ & 1 & 7 & 5 & 1 & $1 / 5$ & 3 & 1 \\
\hline \multicolumn{10}{|c|}{ Evaluator 3} \\
\hline Criterion & \multicolumn{3}{|c|}{ Criterion 1} & \multicolumn{3}{|c|}{ Criterion 2} & \multicolumn{3}{|c|}{ Criterion 3} \\
\hline NS & NS-E1 & NS-E2 & NS-E3 & NS-E1 & NS-E2 & NS-E3 & NS-E1 & NS-E2 & NS-E3 \\
\hline NS-E1 & 1 & $1 / 2$ & 2 & 1 & $1 / 3$ & $1 / 6$ & 1 & 9 & 7 \\
\hline NS-E2 & 2 & 1 & 4 & 3 & 1 & $1 / 4$ & $1 / 9$ & 1 & $1 / 3$ \\
\hline NS-E3 & $1 / 2$ & $1 / 4$ & 1 & 6 & 4 & 1 & $1 / 7$ & 3 & 1 \\
\hline
\end{tabular}

Table 9. Hierarchy of the nutritional solutions based on herbal plants

\begin{tabular}{c|cccc}
\hline Evaluator 1 & $\mathbf{C 1}$ & $\mathbf{C 2}$ & $\mathbf{C 3}$ & Hierarchy \\
\cline { 1 - 4 } Ev1C & $\mathbf{0 . 0 8 1}$ & $\mathbf{0 . 1 8 8}$ & $\mathbf{0 . 7 3 1}$ & \\
NS-E1 & 0.258 & 0.081 & 0.770 & 0.599 \\
NS-E2 & 0.637 & 0.188 & 0.068 & 0.137 \\
NS-E3 & 0.105 & 0.731 & 0.162 & 0.264 \\
\hline Evaluator 2 & $\mathbf{C 1}$ & $\mathbf{C 2}$ & $\mathbf{C 3}$ & Hierarchy \\
\hline Ev2C & $\mathbf{0 . 1 8 8}$ & $\mathbf{0 . 0 8 1}$ & $\mathbf{0 . 7 3 1}$ & \\
NS-E1 & 0.238 & 0.094 & 0.742 & 0.595 \\
NS-E2 & 0.625 & 0.167 & 0.075 & 0.186 \\
NS-E3 & 0.136 & 0.740 & 0.183 & 0.219 \\
\hline Evaluator 3 & $\mathbf{C 1}$ & $\mathbf{C 2}$ & $\mathbf{C 3}$ & Hierarchy \\
\hline NS-E1 & $\mathbf{0 . 0 7 3}$ & $\mathbf{0 . 1 6 6}$ & $\mathbf{0 . 7 6 1}$ & \\
NS-E2 & 0.286 & 0.091 & 0.785 & 0.634 \\
NS-E3 & 0.571 & 0.218 & 0.066 & 0.128 \\
& 0.143 & 0.691 & 0.149 & 0.238 \\
\hline
\end{tabular}

The average value of the final weights obtained for the three nutritional solutions indicates that NSE1 (0.609) is better than NS-E3 (0.240) which is better than NS-E2 (0.150). 
Regarding this set of data, the best alternative for feeding the broiler chickens in order to reduce the nitrogen pollution of the environment is NS-E1, which uses basil as a supplement.

\section{CONCLUSIONS}

The present study highlights the useful of AHP methodology in selection of best nutritional solution for broiler chickens, diet enriched with phytoadditives (basil, thyme, sage) in order to reduce the nitrogen pollution of the environment, but also preserved or increasing the level of animal byproducts quality and nutrient digestibility.

The nutritional solution containing basil or basil oil proved to be the most suitable for the proposed objective. An addition of $0.1 \%$ of basil or $0.05 \%$ of oil basil reduced the nitrogen emission in the environment, even this is cuantified as nitrogen digestibility or nitrogen content in manure.

This study can be a important step forward, in order to reduce nitrogen pollution generated by the manure in chicken production activities and to increase herbals in nutrition solutions among poultry producers.

\section{ACKNOWLEDGEMENTS}

The authors acknowledge the financial support offered by Romanian Ministry of Agriculture and Rural Development, through “Agriculture and Rural Development - ADER 2022” Program, Project code ADER 9.1.2./2019.

\section{REFERENCES}

[1] PHILliPS, A. L., FAUSTMAN, C., LYNCH, M. P., GOVONI, K. E., HOAGLAND, T. A., ZINN, S. A., Meat Sci., 58, 2001, p. 389.

[2] NIETO, G., ROS, G., CASTILlO, J., Medicines, 5, no. 3, 2018, p. 98, https://doi.org/10.3390/medicines5030098

[3] JERONIMO, E., ALFAIA, C.M.M., ALVES, S.P., DENTINHO, M.T.P., PRATES, J.A.M., VASTA, V., SANTOS-SILVA, J., BESSA, R.J.B., Meat Sci., 92, no. 4, 2012, p. 841, https://doi.org/10.1016/j.meatsci.2012.07.011

[4] ZHANG, Y., LUO, H., LIU, K., JIA, H., CHEN, Y., WANG Z., Meat Sci., 2015, 105, p. 38.

[5] BOTSOGLOU, N., FLOROU-PANERI, P., BOTSOGLOU, E., DOTAS, V., GIANNENAS, I., KOIDIS, A., MITRAKOS, P., S. Afr. J. Anim. Sci., 35, 2005, p. 143.

[6] VLAICU, P. A., PANAITE, T. D., TURCU, R. P., TABUC, C. Rom. Biotechnol. Let., 25, no 5, 2020, p. 1922. doi: 10.25083/rbl/25.5/1922.1929

[7] GURBUZ, Y., ISMAEL, I. A., Iran. J. Appl. Anim. Sci., 6, no. 1, 2016, p. 149.

[8] ABBAS, R. J., Int. J. Poult. Sci, 9, no. 3, 2010, p. 278.

[9] PHILliPS, A. L., FAUSTMAN, C., LYNCH, M. P., GOVONI, K. E., HOAGLAND, T. A., ZINN, S. A., Meat Sci., 58, 2001, p. 389.

[10] CROSS, D.E., MCDEVITT, R.M., HILlMAN, K., ACAMOVIC, T., Brt. Poult. Sci., 48, no. 4, 2007, p. 496.

[11] BARAKAT, D., EL-FAR, A.H., SADEK, K., MAHROUS, U., ELLAKANY, H., ABDELLATIF, M., Int. J. Pharm. Sci. Rev. Res., 37, 2016, p. 134.

[12] ABDEL-GHANEY, D.M., EL-FAR, A.H., SADEK, K.M., EL-SAYED, Y.S., ABDEL LATIF, M.A., Alex. J. Vet. Sci., 2017, 55, no.1, p. 169, https://doi.org/10.5455/ajvs.275352.

[13] RASOULI, B., MOVAHHEDKHAH, S., SEIDAVI, A., HAQ, Q.M.I, KADIM, I., LAUDADIO, V., MAZZEI, D., Agrofor. Syst., 94, 2019, p. 1179, https://doi.org/10.1007/s10457019-00401-8.

[14] AL-SHERIFY, M.H.S., AL-ALWANY, J.A.A., J. Nat. Sci. Res., 2016, 6, no. 6, p. 131.

[15] SAATY, T.L., Int. J. Serv. Sci., 1, no.1, 2008, p. 83, https://doi.org/10.1504/IJSSCI.2008.017590.

[16] SAATY, L., VARGAS, L.G., Models, Methods, Concepts \& Applications of the Analytic Hierarchy Process, Springer, Boston, 2012, p. 1-39, https://doi.org/10.1007/978-1-4614-3597-6.

[17] ARAMA, M., CRISTE, I.V., CRISTE, R.D., PANAITE, T., Arch. Zootech., 18, no. 2, 2015, p. 73. 
[18] HO, W., Eur. J. Oper. Res, 2008, 186, no. 1, p. 211.

[19] DANNER, M., GERBER-GROTE, A., Patient Involvement in Health Technology Assessment, Springer Nature, Singapore, 2017, p. 135-147, https://doi.org/10.1007/978-981-10-4068-9_11.

[20] YI, Z., WEI, W., LANGFENG, M., SIQI, W., FENGYAN, Z., LIXIN, L., Chem Technol Fuels Oils, 56, 2020, p. 236, https://doi.org/10.1007/s10553-020-01134-6.

[21] VAIDYA, O.S., KUMAR, S., Eur. J. Oper. Res., 169, no. 1, 2006, p. 1.

Citation: Vasile, G.G., Tenea, A.G., Serban, E.A., Catrina, G.A., Badescu, V., Vlaicu, P.A., Ranking the dietary treatments of broiler chickens in order to reduce nitrogen pollution of the environment, Rom. J. Ecol. Environ. Chem., 2021, 3, no.2, pp. 99-106.

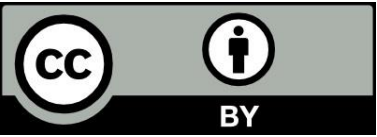

(C) 2021 by the authors. This article is an open access article distributed under the terms and conditions of the Creative Commons Attribution (CC BY) license (http://creativecommons.Org/licenses/by/4.0/). 